\title{
All my children: The roles of semantic category and phonetic similarity in the misnaming of familiar individuals
}

\author{
Samantha A. Deffler ${ }^{1}$ • Cassidy Fox ${ }^{1}$ • Christin M. Ogle ${ }^{1}$ - David C. Rubin ${ }^{1,2}$
}

Published online: 22 April 2016

(C) Psychonomic Society, Inc. 2016

\begin{abstract}
Despite knowing a familiar individual (such as a daughter) well, anecdotal evidence suggests that naming errors can occur among very familiar individuals. Here, we investigate the conditions surrounding these types of errors, or misnamings, in which a person (the misnamer) incorrectly calls a familiar individual (the misnamed) by someone else's name (the named). Across 5 studies including over 1,700 participants, we investigated the prevalence of the phenomenon of misnaming, identified factors underlying why it may occur, and tested potential mechanisms. We included undergraduates and MTurk workers and asked questions of both the misnamed and the misnamer. We find that familiar individuals are often misnamed with the name of another member of the same semantic category; family members are misnamed with another family member's name and friends are misnamed with another friend's name. Phonetic similarity between names also leads to misnamings; however, the size of this effect was smaller than that of the semantic category effect. Overall, the misnaming of familiar individuals is driven by the relationship between the misnamer, misnamed, and named; phonetic similarity between the incorrect name used by the misnamer and the correct name also plays a role in misnaming.
\end{abstract}

Keywords Memory $\cdot$ Semantic memory $\cdot$ Memory errors · Recall

Samantha A. Deffler

samantha.deffler@duke.edu

1 Department of Psychology and Neuroscience, Duke University, Box 90086, Durham, NC 27708, USA

2 Center on Autobiographical Memory Research, Aarhus University, Aarhus, Denmark
"Becky . . . Jesse . . . Molly . . . no, Samantha! Help me with the groceries," your mother yells, looking at you. Each of the authors, though different in gender, age, and background, have been called a sibling's name by an older family member who actually knew who we were; for three of us who owned a dog, we were even called the dog's name. The last author, having experienced this seeming insult by loving parents as a child, now does it to his graduate students, and he only has two. This could not be simply part of the aging process; a young adult calling a romantic partner by another real or imagined partner's name (e. g., "I, Ross, take thee, Rachel...") is a common plot line in popular culture. Instead of leaving this as a laboratory joke, we decided to study it because, despite the prevalence of research into the retrieval of proper names that are low in familiarity (e.g., Burke, MacKay, Worthley, \& Wade, 1991; Cohen, 1990; McKenna \& Warrington, 1980), very few studies have looked at how the names of highly familiar (noncelebrity) people are retrieved, or more interestingly, incorrectly retrieved. More formally, we investigate the conditions surrounding these types of errors, or misnamings, in which a person (the misnamer) incorrectly calls a familiar individual (the misnamed) by the name of someone else (the named).

In spite of the anecdotal data suggesting that misnamings are a common phenomenon, we could find only two diary studies that examine the phenomenon of individuals misnaming those whom they know personally. Young, Hay, and Ellis (1985) had participants record errors in person recognition, including not recognizing a familiar person and difficulty retrieving a person's name. Of interest here, roughly one-third of the reports were for the misidentification of a familiar person. The authors suggest that these misnamings occurred because of both semantic (within the same category) and physical similarity between the misnamed and the named. Cohen and Faulkner (1986; also see Burke et al., 1991) also questioned people about naming blocks (the inability to recall 
a name), although their focus was on age differences. No naming blocks for relatives were reported, but the majority of naming difficulties reported did occur for friends and acquaintances. When trying to retrieve the correct name, people reported recalling the names of those semantically similar to the individual in question, suggesting that proper names are linked with other semantic information about a person that in turn connects them to similar individuals.

Other studies have examined difficulty in remembering the correct names of moderately well-known individuals rather than the problem of easily remembering a wrong name for a personally known individual. For example, research on the naming of celebrities has shown that naming blocks or misnaming of celebrities can occur (Brédart, 1993; Griffin, 2010; Young, Ellis, \& Flude, 1988), but these misnamings may be qualitatively different from misnaming a personally and well-known individual. However, given the paucity of data on the phenomenon of interest, these studies also provide useful sources of information and hypotheses. In one misnaming study by Griffin (2010), college students were asked to recognize the faces of well-known celebrities. When subjects failed at recognizing the celebrities, they did not make random errors. Instead, celebrities that were misrecognized were mistaken for individuals with similar characteristics. These characteristics were occasionally physical, but errors also occurred because of similarities in nationality and profession. For instance, President Kennedy was mistaken for President Regan, and Elizabeth I was mistaken for Mary, Queen of Scots. This observed semantic relatedness between misnamed individuals and named individuals is consistent with a possible mechanism by which misnaming occurs: semantic information activated by seeing or thinking of a person can cause the incorrect activation of another person's name because those people are within the same group or semantic category (here, family, friends, or other).

Results of these studies are consistent with the interactive activations and competition model of person recognition (Brédart, Valentine, Calder, \& Gassi, 1995; Burton, Bruce, \& Hancock, 1999; Burton, Bruce, \& Johnston, 1990), which posits that information about a person is coded as a shared semantic unit or category (e.g., relative, friend); activation of a semantic unit can spread to facilitate retrieval of other individuals within the same unit. This shared semantic information can lead to associative and categorical priming when naming closely related individuals (Carson \& Burton, 2001; Darling \& Valentine, 2005; Vladeanu, Lewis, \& Ellis, 2006; see Stone, 2008, for a more nuanced examination of the associative vs. categorical priming debate). Names of people within a given category can even cause proactive interference for the name of a known individual (Darling, Martin, \& Macrae, 2010), and release from proactive interference occurs when new, unrelated semantic information is retrieved (Darling \&
Valentine, 2005). Here we attempt to extend these findings to the misnaming of well-known individuals.

Consistent with the difficulty in recall, the names of known individuals are also more vulnerable to tip-of-the-tongue (TOT) states than common nouns (Reason \& Lucas, 1984). A TOT occurs when one feels that information is known but cannot recall it (Brown, 1991). In a survey of TOT states, Burke and colleagues (1991) found that the majority of TOTs reported by participants were for the names of acquaintances with which they had not recently been in contact. In a study of TOT states for celebrity names, Hanley and Chapman (2008) found that celebrities who were lower in familiarity were more likely to elicit a TOT state; here, both semantic (familiarity) and phonetic (two names, e.g., Meryl Streep; vs. three, e.g., Helena Bonham Carter) factors affected the prevalence of TOT states. TOT states may occur because a more accessible word, or persistent alternative, is currently in the individual's consciousness and therefore blocks the production of the target word. Cross and Burke (2004) attempted to determine if the presentation of target words could be used to increase TOT states. However, when individuals were primed with an incorrect but plausible name (the name of a character a celebrity played), TOT states did not increase. Having more knowledge about a particular word also did not increase the prevalence of TOT states (Cross \& Burke).

TOT states may be related to the phenomenon of misnaming because they involve a failure to retrieve a name and include the production of alternate names that are similar to the "persistent alternatives" in TOT states. However, a key difference between the occurrences that we are exploring and TOT states is the quick retrieval of an incorrect name during misnaming (as opposed to the effortful and temporally disjointed attempt to recall during a TOT state). Misnaming involves the fluid replacement of the misnamed's correct name with an incorrect (but often plausible) name. In its fluidity, misnaming is more akin to pronunciation errors or slips of the tongue (Bomer \& Laver, 1968; Freud, 1901/2009; Motley, Baars, \& Camden, 1983), such as spoonerisms, malapropisms, and word substitutions (e.g., "runny babbit," "weapons of mass production," and "on my elbow" versus "on my knee," respectively; Dell \& Reich, 1981; Fay \& Cutler, 1977; Motley, Camden, \& Baars, 1982). Similar to some of these examples, misnaming may also be influenced by the phonetics of names, or occur at the phonological feature layer of a spreading activation network (Berg, 2006; Dell, 1986). For example, similarly sounding words can prime proper nouns (e.g., cherry pit primes Brad Pitt; Burke, Locantore, Austin, \& Chae, 2004). We therefore test whether phonetic similarity plays a role in the misnaming of familiar individuals.

The aims of the current study are threefold. First, we intend to show that misnaming of familiar individuals is a widespread phenomenon. Second, we will establish the parameters by which it tends to occur. Because few studies have explored the misnaming of personally known individuals, we examine 
a wide variety of potential factors that may lead to this phenomenon. We derived self-report measures from existing literature and from anecdotal reports of the misnaming phenomenon to examine the circumstances surrounding misnaming. Third, we test the two potential mechanisms that the literature indicates are most likely to influence misnaming: (1) semantic relatedness, with the semantic category in which the misnamed belongs (e.g., family, friend) influencing the names that he or she is called; and (2) phonetic similarity between the incorrect name used and the correct name.

We use five studies to establish the phenomenon of misnaming familiar individuals and describe its properties. Study 1 establishes that about half of the over 1,500 undergraduates we screened have been misnamed by familiar individuals. Studies 2, 3, 4, and 5 explore the phenomenon, document its properties, and test our hypotheses regarding the mechanism(s) underlying misnaming. To ensure the generalizability of our results over different populations, Studies 2 and 4 test undergraduate volunteers, whereas Studies 3 and 5 replicate these using a more age-diverse, paid adult sample. Studies 2 and 3 measure the phenomenon from the perspective of the misnamed whereas Studies 4 and 5 measure it from the perspective of the misnamer, providing somewhat different information and further replications.

\section{Study 1: Demonstration of phenomenon}

\section{Method}

Participants Duke University undergraduates participated in the study as part of a department-wide, web-based questionnaire used to select participants for future studies. Across five semesters, a total of 1,544 undergraduates were given a brief questionnaire about instances of misnaming. Of the 1,544 undergraduates who participated in the larger survey, 25 declined to answer the questions about misnaming. The final sample included 1,519 individuals and was $61.1 \%$ female. The mean age of the participants was 18.76 years $(S D=$ 1.03; range: 17-23). These data were also used to recruit participants for Studies 2 and 4.

Procedure All participants answered the following questions: (1) Have you ever been called the wrong name by someone familiar to you? and (2) What is your relationship to this person? A subset of participants $(N=799)$ also answered (1) Have you ever called someone familiar to you by the wrong name? and (2) What is your relationship to this person?

\section{Results}

Of participants who provided data, $51.0 \%$ reported that they had been misnamed by someone familiar to them. If misnamed,
$95.0 \%$ of the participants were called the incorrect name by a family member. Of all of the female participants, $55.3 \%$ reported being misnamed and $44.7 \%$ did not. Of all of the male participants, $44.3 \%$ of males reported being misnamed and $55.7 \%$ did not, indicating a relationship between gender and being misnamed, $\chi^{2}(1)=17.32, p<.001, \varphi=.11$.

Within the subset of participants asked about misnaming a familiar individual, $38.3 \%$ reported misnaming a familiar person. If they had misnamed someone, $55.1 \%$ reported misnaming a family member and $41.0 \%$ reported misnaming a friend. Of the female participants, $41.1 \%$ reported misnaming and $58.9 \%$ did not. Of the male participants, $33.2 \%$ reported misnaming and $66.8 \%$ did not, indicating a relationship between gender and being misnamed, $\chi^{2}(1)=$ 4.87, $p=.03, \varphi=.08$. Reporting committing a misnaming was related to reporting being misnamed, with participants more likely to report both occurrences or neither type of occurrence, $\chi^{2}(1)=182.77, p<.001, \varphi=.48$.

\section{Study 2: Misnaming of undergraduates by known individuals}

Given that misnaming by familiar individuals is a widespread phenomenon, the goal of Study 2 was to understand the circumstances under which misnamings occur (e.g., when it occurs and who misnames whom). To that end, we gave undergraduates a longer survey about particular misnaming episodes, with more specific questions that were derived from data about misnaming incidents from a pilot study with Duke students.

\section{Method}

Participants One-hundred and nineteen Duke University undergraduates (56.3\% female) who had reported being misnamed in Study 1 were recruited to complete an online survey. The mean age of the participants was 18.97 years $(S D=.91$; range: $18-22)$.

Procedure Participants were directed to an online Qualtrics survey, where they consented to participate. After reading the instructions, all participants completed the misnaming and demographics portion of the survey.

\section{Measures}

Misnaming information Participants were asked to report up to 10 incidents of misnaming. For each instance of misnaming, participants were first asked to (1) identify the person who had misnamed them, (2) indicate whether they had been called one name or a string of names, and (3) indicate, if called multiple names, whether the incorrect names 
were always said in the same order. Participants were then asked what name(s) they had been called, as well as their relationship to the individuals with whom their names were switched. Participants also rated the misnaming episode on a number of different dimensions shown in Table 1. One dimension asked how often this type of misnaming occurred (rarely, yearly, every few months, monthly, and daily or more often). We categorized these responses into two bins: rarely, yearly, or every few months (Bin 1); and monthly, daily, or more often than daily (Bin 2).

For each misnaming incident, we also coded the phonetic similarity of the participant's name and the name that he or she was wrongly called in two ways. First, phonetic similarity was independently rated by two coders on a scale from 0 to $2(0=$ no similarity, $1=$ somewhat similar, $2=$ similar , and the ratings showed high reliability, $K=.77$. Disagreements were scored by a third independent coder. The third coder's ratings were retained in all cases of disagreement. Names were rated as similar if they had identical beginning and ending sounds (e.g., Michael and Mitchell) or if they had multiple letter similarity at the beginning (e.g., Phillip and Phyllis). Names were rated as somewhat similar if they shared a beginning sound (e.g., Abigail and Agatha; Felicity and Phyllis) or if they shared a common ending sound (e.g., Joey and Mikey). Names with none of these features in common were rated as not similar.

Second, we analyzed the number of overlapping phonemes between the names. Each name was translated into the International Phonetic Alphabet (IPA) by using an online dictionary based upon the Carnegie Mellon University Pronouncing Dictionary. Next, a trained linguist checked the translations for correctness as well as translated names that were not processed by the dictionary. A proportion of phonetic overlap between the used name and the correct name was then calculated by counting the number of phonemes in the used

Table 1 Misnamed and Misnamer Demographics and Characteristics of Episodes

\begin{tabular}{|c|c|c|c|c|}
\hline & Study 2 & Study 3 & Study 4 & Study 5 \\
\hline$N$ of Participants & 119 & 97 & 67 & 94 \\
\hline$N$ of Episodes & 292 & 207 & 212 & 193 \\
\hline \multicolumn{5}{|l|}{ Misnamed Demographics } \\
\hline$\%$ Female & $56.3 \%$ & $52.6 \%$ & $61.3 \%$ & $51.3 \%$ \\
\hline Age $M(S D)$ & $18.97(.91)$ & $33.51(10.85)$ & $22.44(11.87)$ & $28.26(18.17)$ \\
\hline Age Range & $18-22$ & $19-64$ & $2-70$ & $1-85$ \\
\hline \multicolumn{5}{|l|}{ Misnamer Demographics } \\
\hline$\%$ Female & $60.6 \%$ & $54.6 \%$ & $88.2 \%$ & $57.4 \%$ \\
\hline Age $M(S D)$ & $47.24(18.08)$ & $53.47(21.86)$ & $18.80(.92)$ & $36.52(13.52)$ \\
\hline Age Range & $9-95$ & $3-95$ & $18-21$ & $18-74$ \\
\hline$\%$ Older than Misnamed & $83.0 \%$ & $73.7 \%$ & $14.5 \%$ & $53.1 \%$ \\
\hline $\begin{array}{l}\text { Do the misnamer and misnamed see each other } \\
\text { or speak regularly ( } \% \text { yes })\end{array}$ & $78.1 \%$ & $64.7 \%$ & $78.7 \%$ & $74.1 \%$ \\
\hline \multicolumn{5}{|l|}{ Characteristics of Episodes } \\
\hline \multicolumn{5}{|l|}{ How often does this type of misnaming occur? } \\
\hline Rarely, yearly, or every few months & $64.5 \%$ & $57.7 \%$ & $59.8 \%$ & $66.3 \%$ \\
\hline Monthly, daily, or more often than daily & $35.5 \%$ & $42.3 \%$ & $40.2 \%$ & $33.7 \%$ \\
\hline \multicolumn{5}{|l|}{ Was the named called a single name or string of names? } \\
\hline Single & $66.4 \%$ & $72.5 \%$ & $85.8 \%$ & $82.9 \%$ \\
\hline String & $33.6 \%$ & $23.2 \%$ & $14.2 \%$ & $17.1 \%$ \\
\hline If string, end with correct? (\% yes) & $98.0 \%$ & $89.6 \%$ & $100.0 \%$ & $90.9 \%$ \\
\hline Was the misnamed within sight of misnamer? (\% yes) & $79.8 \%$ & $63.3 \%$ & $79.6 \%$ & $70.5 \%$ \\
\hline Was the misnamed asking for something? (\% yes) & $55.5 \%$ & $51.7 \%$ & $40.7 \%$ & $54.9 \%$ \\
\hline Was the misnamer tired, frustrated, or angry? (\% yes) & $44.9 \%$ & $44.0 \%$ & $60.8 \%$ & $43.2 \%$ \\
\hline Was the named present when the misnaming occurred? (\% yes) & $55.2 \%$ & $49.3 \%$ & $56.9 \%$ & $54.5 \%$ \\
\hline Was the named a pet? (\% yes) & $4.5 \%$ & $1.9 \%$ & $3.3 \%$ & $4.7 \%$ \\
\hline If a pet, was the pet owned at the time? (\% yes) & $92.3 \%$ & $100 \%$ & $100 \%$ & $100 \%$ \\
\hline How physically similar is the misnamed to the named? $M(S D)$ & $4.58(1.61)$ & $3.91(1.82)$ & $3.23(1.87)$ & $3.46(2.01)$ \\
\hline
\end{tabular}

Note. Ns refer to number of valid cases. Perceived physical similarity rated on a Likert scale from 1 (not at all similar) to 7 (very similar) 
name that were also present in the correct name, and dividing this number by the number of phonemes in the correct name.

Demographics Questions included the participants' age, gender, race/ethnicity, and languages spoken. In addition to information about the participants, the demographic section also asked participants to describe their family members, pets, and anyone who was mentioned in the previous sections. For each person mentioned, they were asked to list their relationship, perceived physical similarity $(1=$ not at all similar to $7=$ very similar) between the person and themselves, and whether the person lived with them or not. For each pet mentioned, they were asked the pet's type, gender, and whether the pet was currently owned. Participants were also prompted to include information for all of the individuals that had been mentioned previously when describing misnaming incidents. Later, the names and demographics of these individuals were matched to the information pertaining to each misnaming incident in which they or their names were involved.

\section{Results and discussion}

Participants provided a total of 292 cases of misnaming. Note that here and in the subsequent studies, because of missing data, some frequencies do not sum to the total $N$, and some percentages may not sum to $100 \%$. Here and throughout the paper, we report all of our results, but mainly discuss those that address our hypotheses. (See Table 1 for the relevant data on the demographics of the misnamer and misnamed, as well as characteristics of the misnaming incidents.) To summarize, misnamers were more often female than male, were almost always older than the misnamed, and saw or spoke to the misnamed regularly. Each reported misnaming was typically experienced every few months, yearly, or rarely, and the misnamed tended to be called a single name only during a misnaming episode. Perceived negative mood did not have an effect on misnaming.

We also analyzed the qualities of the named individuals whose names were incorrectly used to refer to the misnamed participant. About half of the time, the named individual was present when the misnaming occurred. On average, the named individuals were only somewhat physically similar to the misnamed participants, suggesting that perceived physical similarity between people was not driving misnaming.

Besides the qualitative characteristics of the misnaming event and the individuals involved with misnaming, the relationships between the misnamer, the misnamed, and the named were also examined. Specifically, we were interested in whether misnaming occurred because the misnamed and the named were members of the same group or semantic category (e.g., the same family), and thus their names shared some semantic meaning. The relationships between the misnamer and the misnamed, and the named and the misnamed, were categorized into one of four categories: family members, friends, other humans, and pets. For all following analyses, only the first name reported was analyzed because of the internal similarity of naming strings skewing the results. The relevant data are reported in Table 2; each incident of misnaming was categorized by the relationship between the misnamed and the misnamer (rows) and the relationship between the named and the participant (here, the misnamed; columns). The relationships between the misnamed and the misnamer and the misnamed and the named largely overlapped. In other words, family members tended to misname other family members using a third family member's name, friends tended to misname other friends, and others tended to misname others. When analyzed using chi-square, which assumes independence between the relationship of the misnamer and the misnamed and the relationship between the misnamer and named, the results were significant across all categories. The large value of $\varphi$ (.93) indicates a large effect of semantic relatedness. In this sample, only 13 pets were mentioned, and their names were used exclusively by family members of the misnamed.

The aforementioned results suggest that misnamings occur within semantic categories; however, the analysis did not exclude the possibility that the misnamings also occurred because of phonetic similarity between names. For each measure of phonetic similarity (rated similarity and proportion of phoneme overlap), the phonetic similarity of the incorrect name used by the misnamer to all of the correct names (legal name and nicknames) were averaged. Of all the cases of misnaming ( $n=292$ ), the name used and the correct name were, on average, low on phonetic similarity as rated by research assistants $(M=.33, S D=.45)$, as well as when the proportion of overlapping phonemes between the correct name and the used name was calculated $(M=.34, S D=.22)$. We ran a Monte Carlo procedure to determine a baseline of phonetic similarity by pairing names of all misnamed individuals in the study at random with the incorrect names used across the misnaming incidents and rating these pairs for phonetic similarity, as above $(K=.85)$, as well as calculated the overlapping phonemes between the two names. Here too, the rated phonetic similarity and proportion of phoneme overlap between pairs was low $(M=.18, S D=.34 ; M=.29, S D=.21$, respectively). The rated phonetic similarity of the original name pairs was statistically higher than the randomly generated word pairs, $t(582)=4.61, p<.001, \eta^{2}=.04$, as was the proportion of phoneme overlap, $t(582)=2.68, p=.008, \eta^{2}=.01$.

The similarity of the used name to the correct name was also compared to the results of the Monte Carlo randomization using chi-square analysis (see Table 2). The Monte Carlo ratings were used as expected values for the chi-square calculation. This allows for the comparison of the effect size $\varphi$ between semantic relatedness of the misnamed and the name and the rated phonetic similarity of the correct name and the name used. There was a significant difference between the rated 
Table 2 Relationships Between the Misnamer, Misnamed, and Named Individuals

\begin{tabular}{|c|c|c|c|c|c|c|c|c|c|c|}
\hline \multirow{3}{*}{$\begin{array}{l}\text { Relationship between } \\
\text { misnamed and misnamer }\end{array}$} & \multicolumn{8}{|c|}{ Relationship between participant and named } & \multirow[t]{3}{*}{$\chi^{2}(6)$} & \multirow[t]{3}{*}{$\varphi$} \\
\hline & \multicolumn{2}{|c|}{ Family } & \multicolumn{2}{|c|}{ Friend } & \multicolumn{2}{|c|}{ Other human } & \multicolumn{2}{|l|}{ Pet } & & \\
\hline & Obs & Exp & Obs & Exp & Obs & Exp & Obs & Exp & & \\
\hline Study $2(N=290)$ & & & & & & & & & 252.90 & .93 \\
\hline Family & 201 & 157.2 & 1 & 35.0 & 8 & 19.4 & 6 & 4.5 & & \\
\hline Friend & 6 & 42.2 & 43 & 9.4 & 9 & 5.2 & 0 & 1.2 & & \\
\hline Other Human & 4 & 11.6 & 3 & 2.6 & 9 & 1.4 & 0 & .3 & & \\
\hline Study $3(N=204)$ & & & & & & & & & 142.62 & .84 \\
\hline Family & 111 & 79.5 & 4 & 36.5 & 13 & 13.7 & 5 & 3.3 & & \\
\hline Friend & 9 & 37.7 & 50 & 17.3 & 4 & 6.5 & 0 & 1.5 & & \\
\hline Other Human & 2 & 4.8 & 2 & 2.2 & 4 & .8 & 0 & .2 & & \\
\hline Study $4(N=210)$ & & & & & & & & & 180.48 & .93 \\
\hline Family & 76 & 38.1 & 7 & 47.8 & 3 & 4.0 & 7 & 3.1 & & \\
\hline Friend & 8 & 44.2 & 98 & 55.5 & 2 & 4.6 & 0 & 3.6 & & \\
\hline Other Human & 2 & 3.7 & 3 & 4.6 & 4 & .4 & 0 & .3 & & \\
\hline Study $5(N=190)$ & & & & & & & & & 113.15 & .77 \\
\hline Family & 90 & 60.8 & 9 & 33.9 & 7 & 11.7 & 5 & 4.7 & & \\
\hline Friend & 11 & 35.0 & 46 & 19.5 & 6 & 6.7 & 1 & 2.7 & & \\
\hline Other Human & 3 & 8.2 & 3 & 4.6 & 7 & 1.6 & 2 & .6 & & \\
\hline
\end{tabular}

Note. Obs = observed count; Exp = expected count. For Studies 2 and 3, column headings represent the relationship between the misnamed and the named; for Studies 4 and 5, column headings represent the relationship between the misnamer and the named

phonetic similarity of the observed misnamings and the expected Monte Carlo-generated values, with the observed misname-name pairs rated as more similar than the Monte Carlo pairs. However, the effect size $(\varphi=.49)$ is smaller than the effect of semantic relationships on misnaming $(\varphi=.93)$, Fisher's $Z=13.47, p<.001$.

Consistent with Study 1, these results suggest that instances of misnaming are common occurrences that participants can remember and report on; however, the retrospective nature of the survey may influence these findings. Additionally, misnaming between familiar individuals is not random. Rather, the wrong name used tends to be within the same semantic category and is affected by the phonetic similarity between the correct name and the name used.

\section{Study 3: Misnaming of community-dwelling adults by known individuals}

Study 3 took the same approach as Study 2, but was administered to Amazon Mechanical Turk (MTurk) workers in order to sample from participants of various ages; the MTurk participant population tends to be older and have a wider age range than undergraduates (Buhrmester, Kwang, \& Gosling, 2011), which allows us to better examine characteristics of the relationship between the misnamer and the misnamed. To preview, Study 3 replicates the findings of Study 2 by establishing that misnaming is a common phenomenon among familiar individuals, and it typically occurs within a semantic group.

\section{Method}

Participants Participants were recruited through MTurk and completed an online survey for $\$ 1.00$ compensation; they were told to only complete the survey if they had experienced a misnaming. They were included in the sample only if they correctly answered a "check" question correctly; of 102 participants surveyed, 97 participants $(52.6 \%$ female) did and were included in the sample. The mean age of the participants was 33.51 years $(S D=10.85$; range: 19-64). Most were born in the United States or India $(55.7 \%$ and $27.8 \%$, respectively) and currently resided in those countries (60.8\% and $27.8 \%$, respectively). Participants were also born in Europe (6.2\%), Canada (4.1\%), East Asia (4.1\%), the Middle East (1.0\%), and the South Pacific (1.0\%) and resided in Europe (7.2\%), Canada (2.1\%), East Asia (1.0\%), and the South Pacific (1.0\%). Most participants were native speakers of English (75\%).

Procedure Participants accessed the study through the MTurk website, where they followed a link to a Qualtrics survey. After reading the instructions and answering a "check" question, all participants completed the survey. 
Measures As in Study 2, all participants answered an online survey that queried both demographic information and information about misnaming incidents. The questions were exactly the same as in Study 2, with three exceptions: (1) participants provided their country of origin and their current country of residence; (2) participants were asked what name(s) each individual who has misnamed them called them normally when they had not been misnamed (e.g., what nicknames were used); and (3) whether they see the individual they were misnamed more often than they see the misnamer (this was used to parallel questions in Studies 4 and 5).

Phonetic similarity was rated by two independent coders with high reliability $(K=.81$ for observed name pairs; $K=.89$ for Monte Carlo-generated name pairs) using the same scale as in Study 2; disagreements were scored by a third, independent coder, whose rating was retained in all cases of disagreement. The proportion of overlapping phonemes between the correct name and the name used was also calculated as above.

\section{Results}

Data from Study 3 were analyzed similarly to that of Study 2 . Table 1 presents participant and misnamer demographics and episode characteristics. A total of 207 cases of misnaming were reported. Misnamers in this sample were nearly as often female as male, were typically older than the misnamed, and saw or spoke to the misnamed regularly. Misnamings typically occurred every few months, yearly, or rarely, and participants were usually called only a single name. Once again, perceived negative mood did not have a large effect on misnaming; participants did not often report the misnamer as being tired, frustrated, or angry. As in Study 2, the named individuals were present about half of the time when misnaming occurred. On average, the named individuals were only somewhat physically similar to the misnamed participants.

We were again interested in whether misnaming occurred because the misnamed, the named, and the misnamer were part of the same group or because of phonetic similarity between names. The relationships between the named, the misnamed, and the misnamer largely overlapped (e.g., family members misnamed other family members; see Table 2 ). Regarding phonetic similarity of the name pairs, rated phonetic similarity between the name used and the correct name $(M=.45, S D=$ .53) was significantly greater than the ratings of name pairs randomly assigned through a Monte Carlo procedure $(M=$ $.16, S D=.31), t(412)=6.77, p<.001, \eta^{2}=.10$. For the proportion of overlapping phonemes, the similarity of the observed misnaming pairs $(M=.39, S D=.22)$ was also greater than the Monte Carlo-generated pairs $(M=.30, S D=.19)$, $t(412)=4.32, p<.001, \eta^{2}=.04$. Chi-square analysis of the rated phonetic similarity of the naming pairs (with the Monte Carlo-generated pairs again serving as expected values; see Table 3) showed a significant effect, but the size of the effect
( $\varphi=.68$; see Table 3 ) was smaller than the effect of semantic relatedness $(\varphi=.84)$, Fisher's $Z=3.94, p<.001$.

\section{Study 4: Misnaming of known individuals by undergraduates}

While Studies 2 and 3 provided evidence of the misnaming phenomenon from the perspective of the misnamed, some questions were answered from the perspective of an outside observer. The characteristics of the misnamer, particularly his or her mood at the time of the misnaming incident, are speculative because the participants are reporting times that they are misnamed. We further explore the characteristics of the misnamer in Study 4, in which we query participants on instances where they have called someone the wrong name. As in Study 2, we first investigated this phenomenon in undergraduates.

\section{Method}

Participants Seventy-six Duke University undergraduates (88.2\% female) who had reported committing a misnaming in Study 1 completed an online survey for course credit. The mean age of the participants was 18.80 years $(S D=.92$; range: 18-21). Most of the participants were native speakers of English (94.9\%).

Procedure The procedure was the same as that used in Study 2.

Measures The misnaming information subsection of the questionnaire was altered from that which was used in Studies 2 and 3; here, the focus was on instances when the participants committed a misnaming and therefore would have better insight into the internal states of the misnamer at the time of the misnaming. To parallel the questions asked of the MTurk sample, a question on native language was also added to the Demographics section, but we did not have enough variability in the sample to analyze differences as a function of native language.

Phonetic similarity was rated by two independent coders with high reliability, $K=.81$, using the same scale as in Studies 2 and 3; disagreements were scored by a third, independent coder, whose rating was retained in all cases of disagreement. The proportion of phoneme overlap between the name used and the correct name was again calculated.

\section{Results and discussion}

All data from Study 4 were analyzed in the same manner as that in Studies 2 and 3. A total of 212 cases of misnaming were reported. For this particular sample, the misnamer 
Table 3 Phonetic Similarity Between Correct Name and Misname

\begin{tabular}{|c|c|c|c|c|c|c|c|c|}
\hline \multirow[b]{2}{*}{ Study } & \multicolumn{2}{|c|}{ Not at all similar } & \multicolumn{2}{|c|}{ Somewhat similar } & \multicolumn{2}{|c|}{ Very similar } & \multirow[t]{2}{*}{$\chi^{2}(2)$} & \multirow[t]{2}{*}{$\varphi$} \\
\hline & Obs & $\mathrm{MC}$ & Obs & $\mathrm{MC}$ & Obs & $\mathrm{MC}$ & & \\
\hline Study $2(N=292)$ & 154 & 213 & 114 & 70 & 24 & 9 & 69.00 & .49 \\
\hline Study $3(N=207)$ & 101 & 145 & 82 & 57 & 24 & 5 & 96.52 & .68 \\
\hline Study $4(N=212)$ & 126 & 168 & 77 & 38 & 9 & 6 & 52.03 & .50 \\
\hline Study $5(N=190)$ & 109 & 148 & 67 & 37 & 14 & 5 & 50.80 & .52 \\
\hline
\end{tabular}

Note. Obs = observed count; $\mathrm{MC}=$ Monte Carlo-generated count

demographics are found in the section describing the participants (as they were reporting on times they had called someone the wrong name). The misnamer spoke to the misnamed regularly. Unlike in the previous studies, here the misnamer was often close in age to the misnamed (i.e., less than 3 years age difference; $65.5 \%$ of valid cases), likely because the participants (here, the misnamer) were college students. The number of incidents in which the misnamer was older than the misnamed $(14.5 \%)$ was about the same as the number of incidents where the misnamer was younger than the misnamed $(20.0 \%)$.

As in the previous samples, most misnamings were reported as occurring every few months, yearly, or rarely. Most times, participants only used a single incorrect name when committing a misnaming. Because the participants providing survey data are remembering times they committed a misnaming, the data may be a more accurate representation of the internal and external circumstances of the misnamer at the time of the misnaming (as opposed to Studies 2 and 3, in which the participants were the people being misnamed). When misnamings occurred, the misnamer was usually looking at the misnamed and was not usually asking for something at the time of the misnaming. Here, the misnamers reported being tired, frustrated, or angry when the misnaming episode occurred at a higher rate than the previous two studies. The named individuals were present about half of the time when misnaming occurred. On average, the named individuals were perceived as only somewhat physically similar to the misnamed individuals; this is similar to the finding in Study 3.

Misnamings typically occurred within a group. The relationships between the individuals are reported in Table 2; the categories of the named, misnamed, and misnamer largely overlapped. When the phonetic similarity of the name pairs was examined, the results provided evidence that phonetic similarity plays a role in misnaming. Across all cases of misnaming ( $n=212)$, rated phonetic similarity between the name used and the correct name was low $(M=.40, S D=.53)$, but significantly greater than the ratings of name pairs randomly assigned through a Monte Carlo procedure $(M=.19$, $S D=.43), t(419)=4.58, p<.001, \eta^{2}=.05$. For the proportion of overlapping phonemes, the similarity of the observed misnaming pairs $(M=.39, S D=.20)$ was also greater than the Monte Carlo-generated pairs $(M=.33, S D=.21), t(419)=$ $3.09, p=.002, \eta^{2}=.02$. Chi-square analysis of the rated phonetic similarity of the naming pairs (with the Monte Carlo-generated pairs again serving as expected values; see Table 3) showed a significant effect, but the size of the effect $(\varphi=.50)$ was smaller than the effect of semantic relatedness $(\varphi=.93)$, Fisher's $Z=11.31, p<.001$.

\section{Study 5: Misnaming of known individuals by community-dwelling adults}

Study 5 again investigated misnaming from the perspective of the misnamer, but we increased the age range of the participants by sampling from MTurk in the same manner as in Study 3.

\section{Method}

Participants Participants on MTurk completed a survey for $\$ 1.00$ compensation; they were instructed to only complete the survey if they had committed a misnaming. Participants were screened in the same manner as in Study 3 to ensure they read the survey directions. Of the 105 participants who took the survey, 94 (57.4\% female) correctly answered the check question and were included in the final dataset. The mean age of the participants was 36.52 years $(S D=13.52$; range: 18-74). Most of the participants were born in the United States and currently resided there $(78.7 \%$ \& $86.3 \% \%$, respectively). Participants' regions of origin also included India (8.5\%), South America (6.4\%), Canada (2.1\%), Europe (1.1\%), the Middle East (1.1\%), and Africa (1.1\%). In addition to the United States, participants also resided in India $(8.5 \%)$, Europe $(3.2 \%)$, and South America $(2.1 \%)$. Most of the participants were native speakers of English (91.2\%).

Procedure The procedure was the same as that of Study 3, in that participants were recruited through MTurk and accessed the survey through Qualtrics. The survey measures themselves were identical to that of Study 4. 
Measures The misnaming information subsection of the questionnaire was the same as in Study 4.

Phonetic similarity was rated by two independent coders with high reliability, $K=.76$, using the same scale as in Studies 2, 3, and 4; disagreements were scored by a third, independent coder, whose rating was retained in all cases of disagreement. The proportion of overlapping phonemes between the name used and the correct name was again calculated.

\section{Results and discussion}

The data were analyzed in the same manner as the previous studies. A total of 193 cases of misnaming were reported. Replicating the previous studies, the majority of the misnamings occurred every few months, yearly, or rarely, and misnamers tended to use only one incorrect name (see Table 1). As in Study 4, the participants provided information about times that they had committed a misnaming. Therefore, the misnamer demographics can be found in that section. The misnamer saw or spoke to the misnamed regularly. In approximately half of the misnaming episodes, the misnamer was older than the misnamed. When the misnamings occurred, the misnamer was usually looking at the misnamed. In contrast to Study 4, misnamers reported being tired, frustrated, or angry at the time of the misnaming less often than not. As in the previous studies, the named individuals were present about half of the time when misnaming occurred. Similar to the findings in Studies 3 and 4, on average the named individuals were only somewhat physically similar to the misnamed individuals.

Once again replicating the finding that misnaming was influenced by semantic relationships between the misnamer, the named, and the misnamed, the relationships between these individuals largely overlapped (see Table 2). Furthermore, the phonetic similarity of the named and the misnamed (see Table 3) also factored into misnaming; the rated phonetic similarity of the reported pairs $(M=.44, S D=.59)$ was greater than the randomly paired names $(M=.20, S D=.43), t(384)=$ $4.68, p<.001, \eta^{2}=.05$. The proportion of overlapping phonemes for reported pairs $(M=.39, S D=.23)$ was greater than the proportion of overlap for the Monte Carlo-generated pairs $(M=.29, S D=.20), t(384)=4.29, p<.001, \eta^{2}=.05$. Chisquare analysis of the phonetic similarity of the names showed a significant effect, but as in previous studies, the effect was smaller $(\varphi=.52)$ than that of semantic relatedness $(\varphi=.77)$, Fisher's $Z=4.29, p<.001$.

\section{General discussion}

In five different studies, we investigated the circumstances surrounding the misnaming of personally and well-known individuals by asking both undergraduates and MTurk workers about times that they were misnamed and times in which they had misnamed people familiar to them. Overall, misnaming occurs typically within the same semantic social groups, with family members calling other family members by a wrong name belonging to another family member. Our finding that, across studies, most misnamed-named pairs were rated as only somewhat physically similar suggests that misnaming is likely not due to perceived physical similarity between the named and the misnamed. Our data instead suggest that, similar to studies of TOT states and slips of the tongue, misnaming of highly familiar individuals are influenced by both semantic and phonological factors. Potential substitutions for the correct name may be more likely to be used if they share semantic or phonetic properties with the correct name (Dell \& Reich, 1981; White, Abrams, \& Frame, 2013), which suggests that misnamings can occur at different stages of speech production. A comparison of the effect sizes for semantic similarity and phonetic similarity from the chisquare analysis revealed a larger effect of semantic group that was consistent across all four studies, even though sample characteristics and participant perspective (misnamer or misnamed) varied.

Aggregate analyses also provide interesting insight into the categorization of nonhuman animals, as well as their status within a category. We analyzed all the cases across Studies 2 through 5 that contained at least one pet's name. Of the 42 episodes of misnaming involving pet names, 41 occurred when a family member's name was intended. Of these 41, parents misnamed their children 18 times and siblings misnamed other siblings 16 times with the names of pets. Overall, our data suggested that dogs are grouped with other (human) family members, much more so than other pets. Although cats were owned by our participants about as often as dogs, they were rarely included in a string of incorrect names (of all of the naming strings that contained a pet's name, only four nondog names were used). Given the scarcity of misnaming episodes involving the names of family pets other than dogs, our data suggest that dogs may be a central part of (at least some) families (in fact, two of the authors, S. A. D. and C. F., have distinct memories of being called the dog's name by their mothers) as human-like members, whereas cats and other pets, although they may be part of the family, are not categorized as "human-like." Humans often form unique attachments to dogs (Jalongo, 2015; Sable, 2013) and verbally communicate with them (Prato-Previde, Fallani, \& Valsecchi, 2006), which may lead to increased frequencies of dogs' names used over other pets.

Although the study did lend support to the idea that the misnaming of familiar individuals is semantically and phonetically motivated, it was not without limitations. As with any data collected through self-report, errors in report are possible. Participants may not have fully reported all incidents of misnaming but instead only reported those that were most salient to them at the time. These salient misnamings may give 
an idea of the incidents that are most important to the participants but may not represent the wider phenomenon of misnaming. This subjective self-report may also have influenced our finding that perceived physical similarity did not affect misnaming; our participants may have not been good judges of perceived physical similarity because these judgments can be influenced by irrelevant information (e.g., Imhoff, Dotsch, Bianchi, Banse, \& Wigboldus, 2011; Wenzel, Mummendey, Weber, \& Waldzus, 2003). Furthermore, participants may have engaged in meaningmaking while remembering these events, which could lead to inaccurate responses to the questions regarding the circumstances surrounding the misnaming episodes. Follow-ups to these studies could use a diary method, such as that used by Burke and colleagues (1991), to more accurately capture the circumstances surrounding misnaming. A diary method would also allow us to explore the finding that misnamers were more often female than male. This may be because our participants talked to their female relatives more than their male relatives and these increased interactions lead to more misnaming, but the current data preclude the testing of this hypothesis.

One inconsistency across studies concerned the reported mood of the misnamer at the time of the misnaming incident. With the exception of Study 4 (undergraduates reporting when they committed a misnaming), the proportion of incidents in which the misnamer was in a negative mood state was less than or about equal to the proportion of incidents in which the misnamer was not tired, frustrated, or angry. It is unclear why there was a difference when undergraduates were reporting their own mood, but this may be because of demand characteristics or rationalization of the phenomenon as they remember misnaming events. Another measure of misnamer mood state may be more effective in testing the effects of different mood states on misnaming. We expect that misnamer distraction does affect misnaming incidents, although further research is needed to test this claim.

In closing, the misnaming of familiar individuals is a common phenomenon that has been demonstrated using quantitative techniques and theoretically motivated measures to understand the nature of and circumstances surrounding the misnaming of familiar individuals.

Author note Portions of this project were completed by Cassidy Fox for her Graduation with Distinction Senior Thesis. We thank Irene Lee for help with the phonetic analysis and Kaitlyn Brodar for her editorial assistance.

\section{References}

Berg, T. (2006). A structural account of phonological paraphasias. Brain and Language, 96, 331-356.

Bomer, D. S., \& Laver, J. D. M. (1968). Slips of the tongue. International Journal of Language \& Communication Disorders, 3, 2-12.
Brédart, S. (1993). Retrieval failures in face naming. Memory, 1 , 351-366.

Brédart, S., Valentine, T., Calder, A., \& Gassi, L. (1995). An interactive activation model of face naming. The Quarterly Journal of Experimental Psychology A: Human Experimental Psychology, 48, 466-486.

Brown, A. S. (1991). A review of the tip-of-the-tongue experience. Psychological Bulletin, 109, 204-223.

Buhrmester, M., Kwang, T., \& Gosling, S. D. (2011). Amazon's Mechanical Turk: A new source of inexpensive, yet high-quality, data? Perspectives on Psychological Science, 6, 3-5.

Burke, D. M., MacKay, D. G., Worthley, J. S., \& Wade, E. (1991). On the tip of the tongue: What causes word finding failures in young and older adults? Journal of Memory and Language, 30, 542-579.

Burke, D. M., Locantore, J. K., Austin, A. A., \& Chae, B. (2004). Cherry pit primes Brad Pitt: Homophone priming effects on young and older adults' production of proper nouns. Psychological Science, 15, 164-170.

Burton, A. M., Bruce, V., \& Johnston, R. A. (1990). Understanding face recognition with an interactive activation model. British Journal of Psychology, 81, 361-380.

Burton, A. M., Bruce, V., \& Hancock, P. B. (1999). From pixels to people: A model of familiar face recognition. Cognitive Science, 23, 1-31.

Carson, D. R., \& Burton, A. M. (2001). Semantic priming of person recognition: Categorical priming may be a weaker form of the associative priming effect. The Quarterly Journal of Experimental Psychology, 54A, 1155-1179.

Cohen, G. (1990). Why is it difficult to put names to faces? British Journal of Psychology, 81, 287-298.

Cohen, G., \& Faulkner, D. (1986). Memory for proper names: Age differences in retrieval. British Journal of Developmental Psychology, 4, 187-197.

Cross, E. S., \& Burke, D. M. (2004). Do alternative names block young and older adults' retrieval of proper names? Brain and Language, 89, 174-181.

Darling, S., \& Valentine, T. (2005). The categorical structure of semantic memory for famous people: A new approach using release from proactive interference. Cognition, 96, 35-65.

Darling, S., Martin, D., \& Macrae, C. N. (2010). Categorical proactive interference effects occur for faces. European Journal of Cognitive Psychology, 22, 1001-1009.

Dell, D. S. (1986). A spreading-activation theory of retrieval in sentence production. Psychological Review, 93, 283-321.

Dell, D. S., \& Reich, P. A. (1981). Stages in sentence production: An analysis of speech error data. Journal of Verbal Learning and Verbal Behavior, 20, 611-629.

Fay, D., \& Cutler, A. (1977). Malapropisms and the structure of the mental lexicon. Linguistic Inquiry, 8, 505-520.

Freud, S. (2009). The psychopathology of everyday life (1901). In B. F. Gentile \& B. O. Miller (Eds.), Foundations of psychological thought: A history of psychology (pp. 237-243). Thousand Oaks: Sage (Original work published 1901).

Griffin, Z. M. (2010). Retrieving personal names, referring expressions, and terms of address. The Psychology of Learning and Motivation, 53, 345-387.

Hanley, J. R., \& Chapman, E. (2008). Partial knowledge in a tip-of-thetongue state about two- and three-word proper names. Psychonomic Bulletin \& Review, 15, 156-160.

Imhoff, R., Dotsch, R., Bianchi, M., Banse, R., \& Wigboldus, D. (2011). Facing Europe: Visualizing spontaneous ingroup projection. Psychological Science, 22, 1583-1590.

Jalongo, M. R. (2015). An attachment perspective on the child-dog bond: Interdisciplinary and international research findings. Early Childhood Education Journal, 43, 395-405. 
McKenna, P., \& Warrington, E. K. (1980). Testing for nominal dysphasia. Journal of Neurology, Neurosurgery, and Psychiatry, 43, 781-788.

Motley, M. T., Camden, C. T., \& Baars, B. J. (1982). Covert formulation and editing of anomalies in speech production: Evidence from experimentally elicited slips of the tongue. Journal of Verbal Learning \& Verbal Behavior, 21, 578-594.

Motley, M. T., Baars, B. J., \& Camden, C. T. (1983). Experimental verbal slip studies: A review and an editing model of language encoding. Communication Monographs, 50, 79-101.

Prato-Previde, E., Fallani, G., \& Valsecchi, P. (2006). Gender differences in owners interacting with pet dogs: An observational study. Ethology, 112, 64-73.

Reason, J. T., \& Lucas, D. (1984). Using cognitive diaries to investigate naturally occurring memory blocks. In J. E. Harris \& P. E. Morris (Eds.), Everyday memory actions and absent-mindedness (pp. 5370). London: Academic Press.

Sable, P. (2013). The pet connection: An attachment perspective. Clinical Social Work Journal, 41, 93-99.
Stone, A. (2008). Categorical priming of famous person recognition: A hitherto overlooked methodological factor can resolve a longstanding debate. Cognition, 108, 874-880.

Vladeanu, M., Lewis, M., \& Ellis, H. (2006). Associative priming in faces: Semantic relatedness or simple co-occurrence? Memory and Cognition, 34, 1091-1101.

Wenzel, M., Mummendey, A., Weber, U., \& Waldzus, S. (2003). The ingroup as pars pro toto: Projection from the ingroup onto the inclusive category as a precursor to social discrimination. Personality and Social Psychology Bulletin, 29, 461-473.

White, K. K., Abrams, L., \& Frame, E. A. (2013). Semantic category moderates phonological priming of proper name retrieval during tip-of-thetongue states. Language and Cognitive Processes, 28, 561-576.

Young, A. W., Hay, D. C., \& Ellis, A. W. (1985). The faces that launched a thousand slips: Everyday difficulties and errors in recognizing people. British Journal of Psychology, 76, 495-523.

Young, A. W., Ellis, A. W., \& Flude, B. M. (1988). Accessing stored information about familiar people. Psychological Research, 50, 111-115. 